\title{
Design of Substrate Integrated Waveguide (SIW) Antenna
}

\author{
Hafssa Amer \\ Electrical Engineering Department \\ Baghdad University \\ Baghdad, Iraq
}

\author{
Mahmood A. K. Abdulsattar \\ Electrical Engineering Department \\ Baghdad University \\ Baghdad, Iraq
}

\begin{abstract}
The cavity-backed slots SIW antenna that suitable with planar devices is designed, simulated, implemented, and measured. The design is about of two forms of a slotted cavity at bottom side, but the microstrip line is fed at top side. The feeding line and the cavity-backed slots can be implemented on a single substrate using standard printed circuit board (PCB) process. The idea is to merge specific slot models on the cavity back side such as lateraled and meandered slots. An SIW antenna is presented, the simulation results show a $6.35 \mathrm{~dB}$ gain, $7.3 \mathrm{~dB}$ directivity, and $-0.9512 \mathrm{~dB}(80.33 \%)$ radiation efficiency, and the measurements show that the reflection coefficient $\left(\mathrm{S}_{11}\right)$ at 10.2 $\mathrm{GHz}$ is $-37.23 \mathrm{~dB}$ with a bandwidth of $345 \mathrm{MHZ}$ (3.38 $\%$ ). The combination of cavity-back slots, planar feeding, and SIW antenna design, leads to light weight, size reduction, easy implementation, and simple integration with planar circuits.
\end{abstract}

\section{Keywords}

Cavity-backed, a slot antenna, substrate integrated waveguide (SIW).

\section{INTRODUCTION}

The development of communication devices has managed engineers to require light mass, strength, and simple integration with planar circuit and low-profile antennas [1]. The narrowband frequency is advanced using printed patch antennas [2]. Later, the bandwidth has improvement without reducing the performance of antenna by using cavity backed slot antennas. In addition, it is a suitable solution using of metallic surfaces [3]. To reduce the antenna radiation, a narrow cavity is located behind the slot antenna. In [4], a process for decreasing the sizes of cavity backed rectangular slot antenna is presented.

The substrate integrated waveguide (SIW) has been development and increase by improvement of a new technologies used in passive circuits. The implementation of SIW is suitable when its fabricate by using printed circuit board (PCB) standards. Different offerings have been accounted, so it prevents the original size of passive structures [5]. The SIW technical has been used for designing and fabrication filters and slot antennas [6]. Lately, SIW antenna with a cavity-backed slot that located at the ground plane was proposed [1]. This SIW antenna has some benefits: low cost, size reduction, and compatibility with the PCB process as well as with common surface mounting techniques.

The present work, the improvement of the matching between the transmission line and antenna is obtained by including the lateral slot lines that etching at ground side of SIW antenna. The method of improve the electrical performance of the antenna has been illustrated in [4] by using the meandered slot and how to reduce the cavity width. Finally, compared to [1], the suggested solution leads to reduce the resonant frequency without change the overall dimensions of SIW antenna.

\section{DESIGN PROCEDURE}

The design of the SIW antenna is depend on the use of classical rectangular waveguides analysis equations. Figure 1 shows the classical rectangular waveguide. Then, it can be considering $\left(f_{\mathrm{c}}\right)$ cutoff frequency when working in $\mathrm{TE}_{10}$ fundamental mode. A diagram view of SIW is shown in Figure 2. Such a waveguide is emulating of two parallel arrays of via-holes, which define the waveguide TE wave propagation region. The propagation constant and the radiation loss are determined by parameters "w", "p", and "d", which denote the width of the SIW, the pitch length and the diameter of vias, respectively [7].

$$
\begin{aligned}
f_{C} & =\frac{c}{2 \pi} \sqrt{\left(\frac{m \pi}{a}\right)^{2} \quad+\left(\frac{n \pi}{b}\right)^{2}} \\
f_{c} & =\frac{c}{2 a} \quad \text { At fundamental mode } \\
a_{d} & =a / \sqrt{\epsilon_{r}} \quad \text { Dielectric filled waveguide width } \\
w & =a_{d}+\frac{d^{2}}{0.98 p} \\
\mathrm{w} & =\mathrm{a}_{\mathrm{d}}-1.08 \frac{\mathrm{d}^{2}}{\mathrm{p}}+0.1 \frac{\mathrm{d}^{2}}{\mathrm{a}_{\mathrm{d}}}
\end{aligned}
$$

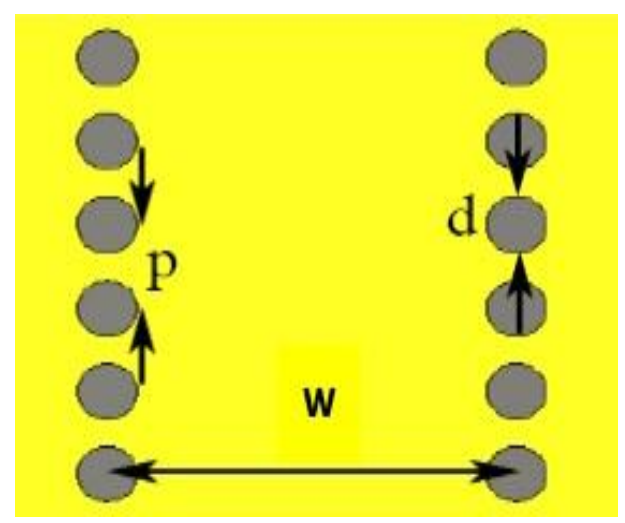

Fig 1: Dimensions of an (SIW)

As shown in Figure 2, the SIW is equivalent to a dielectric filled waveguide with slots at its side, so it can be analyzed just by using the width of the equivalent waveguide [8]. The following is an experimental formula that used to normalize the width of the equivalent waveguide. 
$\bar{w}=\xi_{1}+\frac{\xi_{2}}{\frac{p}{d}+\frac{\left(\xi_{1}+\xi_{2}+\xi_{3}\right)}{\left(\xi_{3}+\xi_{1}\right)}}$

Where

$\xi_{1}=1.0198+\frac{0.3465}{\frac{a}{p}-1.0684}$

$\xi_{2}=-0.1183-\frac{0.3465}{\frac{a}{p}-1.0684}$

$\xi_{3}=1.0082-\frac{0.9163}{\frac{a}{p}+0.2152}$

These formulae have a relative error less $1 \%$ and the width of the equivalent classical rectangular waveguide is [8]:

$a=w * \bar{w}$
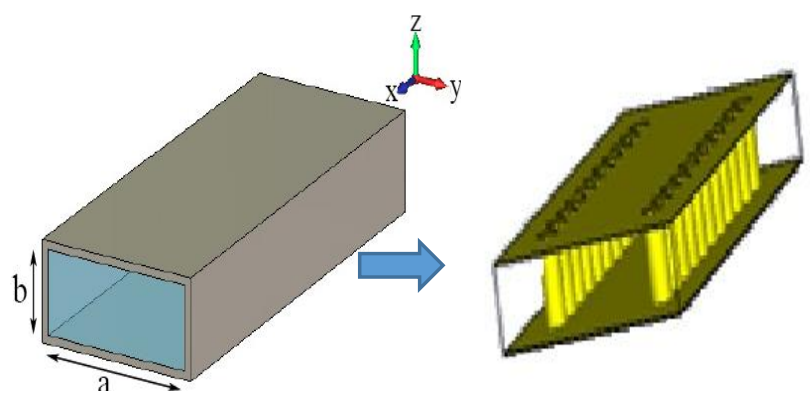

Fig 2: Substrate integrated waveguide and the equivalent rectangular waveguide

Figure 3 shows the analysis results made to implement a cavity with a resonant frequency of $10 \mathrm{GHz}$, over an FR4 substrate $\left(\epsilon_{r}=4.3, \delta=0.025, \mathrm{hs}=1 \mathrm{~mm}\right)$.

\section{EXTERNAL COUPLING TO THE CAVITY USING CPW ACCESS}

A transition between microstrip and SIW cavity as defined in [8] is used on the top side. A 50-microstrip line with length of $\mathrm{Sel}$ that connect to the coplanar waveguide $(\mathrm{CPW})$ as shown in Figure 3. The length $\mathrm{L}_{\mathrm{MS}}$ is used to transform the quasiTEM of the microstrip line into the TE of the SIW antenna. The transition design is easy to achieve, and the quality factor (Q) is largely that effect by the distance $\mathrm{L}_{\mathrm{MS}}$ and the trace width $\mathrm{W}_{\mathrm{M} 2}$. The design circuit is shown in Figure 3.

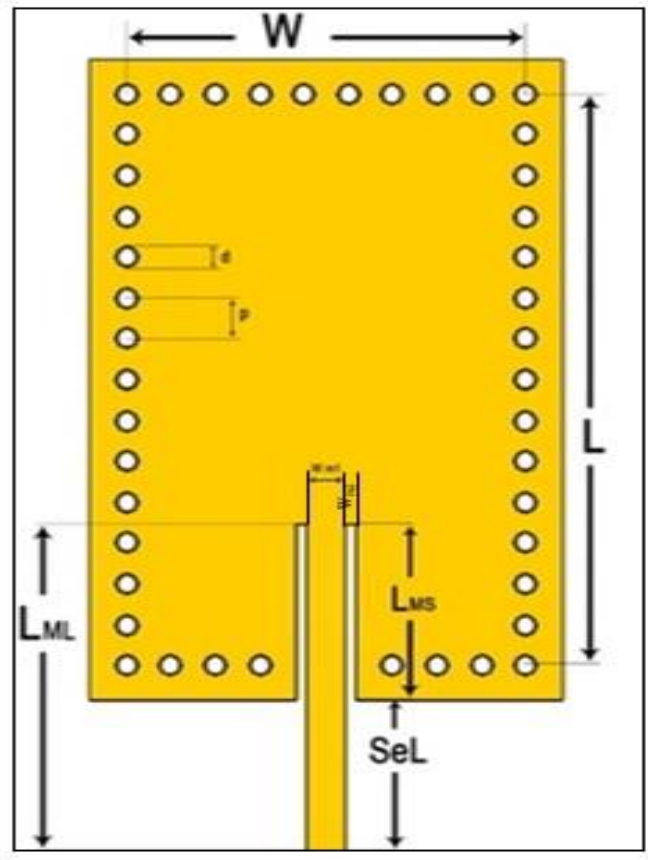

(a)

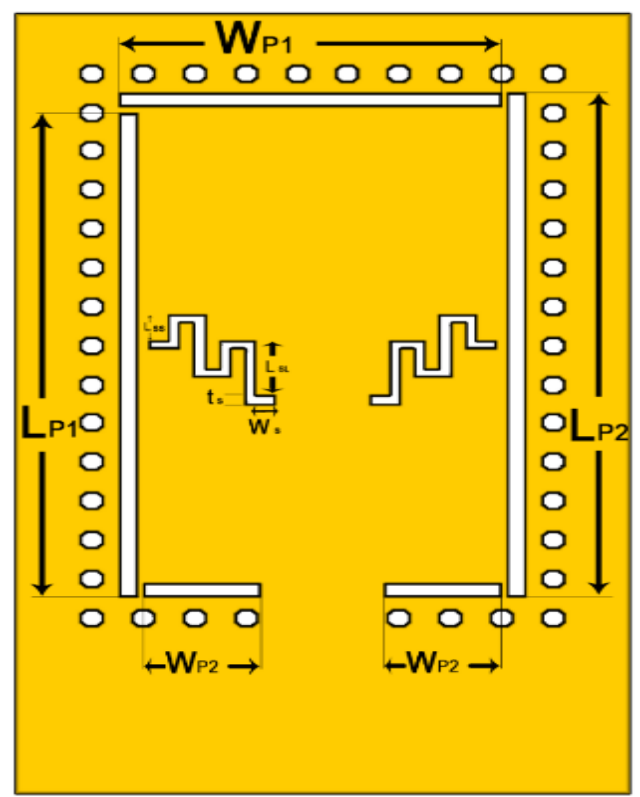

(b)

Fig 3: Circuit topology (a) top view (b) bottom view

\section{ANTENNA EXPLANATION}

A slot patch antenna is typically seen as an equivalent resonant magnetic dipole with its first operating frequency that occurring corresponding to an overall length of $\lambda_{\mathrm{c}} / 2$. Where the compact type of a slot patch antenna can be put into the cavity back metallic plane (bottom face). It is suitable to insert the cavity current lines around the SIW antenna. At first the lateral slot etching on the back side of the SIW antenna, that the five slots (current lines) as rectangle shape are circulated around SIW antenna in perpendicular way as shown in Figure 4, which principally responsible for producing a resonant condition, and it is also responsible for increasing the matching condition between antenna and 
microstrip transmission line. Second, the meandered slots line is etching that conserves the electrical length (Figure 4). These meander slots are responsible to achieve the compact in size without change the overall dimensions of antenna, the meander and lateral slots that etching at bottom side is shown in Figure 4. In the SIW antenna, the maximum current is flowing complete the upper side. The meandered slot line has an overall length $\lambda_{\mathrm{c}} / 2$, and it is of two slots that designed to suitable the cavity width, ending perpendicularly to a lateral slot. Lateral slots are used as inductively load of slot antenna, so the matching of its resonant frequency is change (increased) [9] (Figure 4).

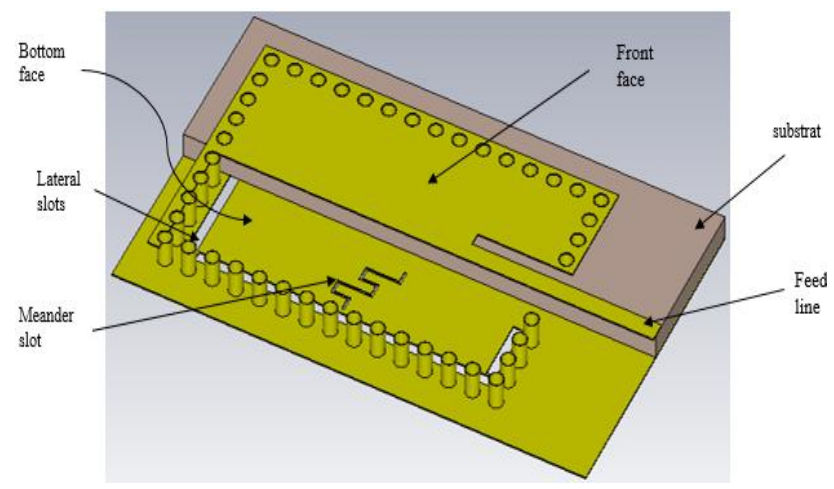

Figure 4: 3D view of the implemented circuit.

\section{SIMULATION RESULTS}

Using the structure before described, was designed of FR4 substrate $\left(\epsilon_{r}=4.3, \delta=0.025, \mathrm{hs}=1 \mathrm{~mm}\right)$. The dimensions of SIW are $9 \mathrm{~mm} \mathrm{X} 14 \mathrm{~mm} \mathrm{X} 1 \mathrm{~mm}$, while the overall antenna dimensions are $12 \mathrm{~mm}$ X $20 \mathrm{~mm}$.

\subsection{Parametric Study}

At first, the SIW antenna is designed to operate at $12.2 \mathrm{GHz}$, the simulation result is shown in Figure5. The lateral slots are including at bottom side of the designed SIW antenna this slots responsible of decreasing the value of the $S_{11}$ parameter from $-19 \mathrm{~dB}$ to $-53 \mathrm{~dB}$ (increase matching between transmission line and SIW antenna) as shown in Figure 6. To obtain compact in size the meander slots are included its responsible for shifting the resonant frequency from $12.2 \mathrm{GHz}$ to $10 \mathrm{GHz}$ (X-band).

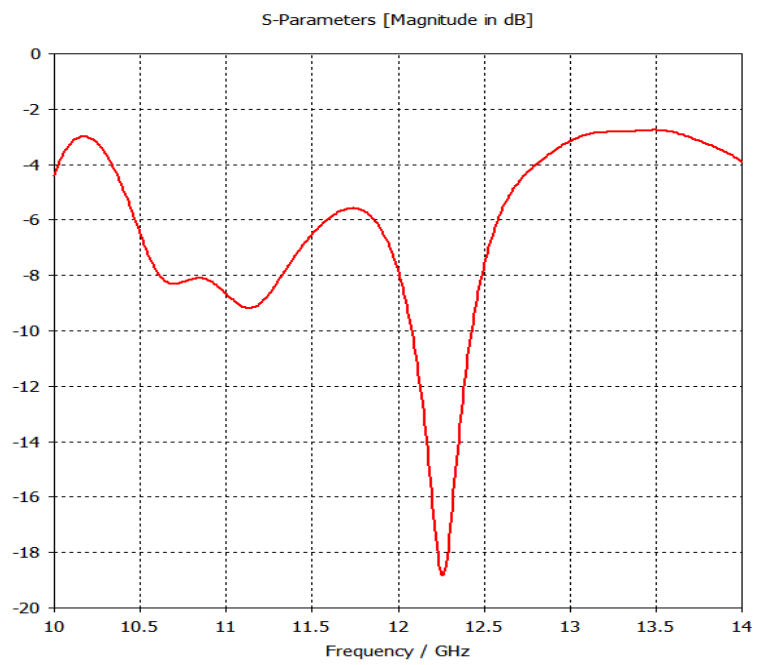

Fig 5: Simulation $S_{11}$-parameter of un slotted proposed SIW antenna

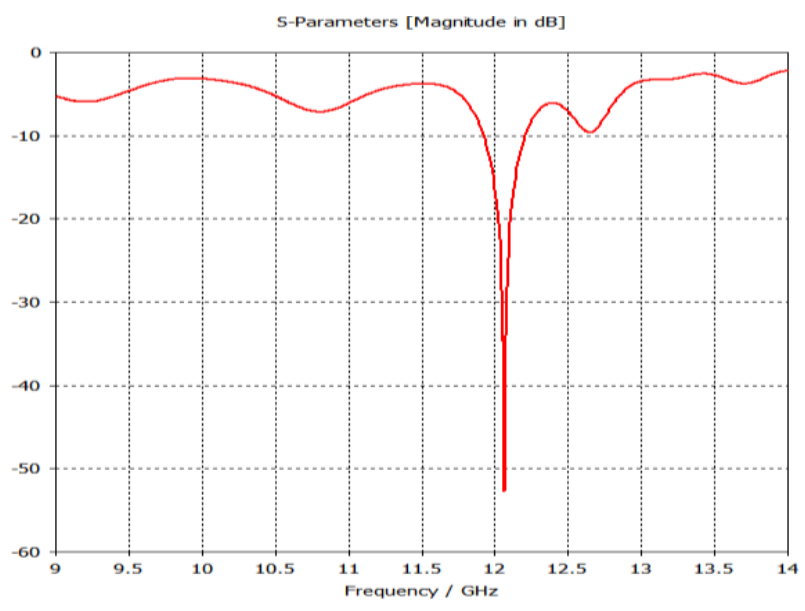

Fig 6: Simulation $S_{11}$-parmeter of cavity back lateral slots SIW antenna

The important parameter that effect on the design of SIW antenna is $t_{s}$. From Figure 7 as $t_{s}$ increases, the value of $S_{11}$ is an increase (matching decrease), but the value of resonant frequency is decreased.

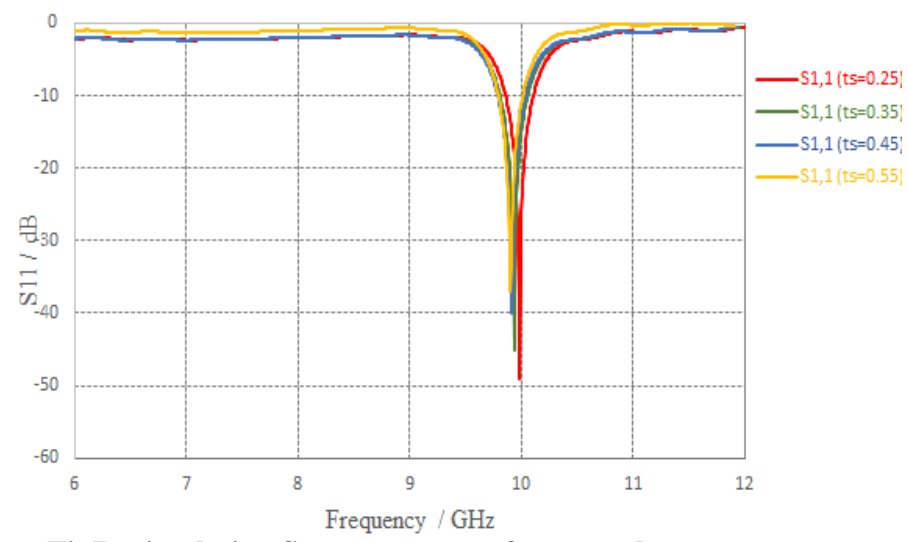

Fig7.: simulation $S_{11}$-parameter of proposed antenna with ts as a parameter

The other parameter that affected on the design of SIW antenna is $t_{p}$. From Figure 8 as $t_{p}$ increase, the value of $S_{11}$ is increase, with the increase of resonant frequency value.

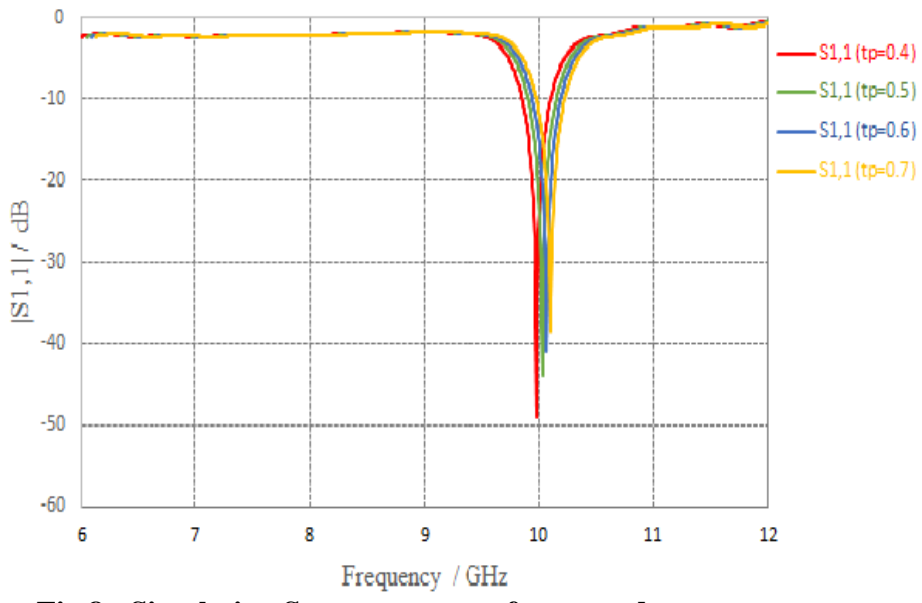

Fig 8:. Simulation $S_{11}$ - parameter of proposed antenna with tp as a parameter 
There must be some compromise between the various requirments of wide bandwidth, low frequency, and low return loss (low $\mathrm{S}_{11}$ ). Final values that are obtained through the sweep parameters and which affect the performance of this antenna have been summarized in table 1. Figure 9 shows a return loss less than $-40 \mathrm{~dB}$ and a fractional bandwidth of about $2.8 \%$ centered at $10 \mathrm{GHz}$. Figure 10 shows the antenna has gain of $6.36 \mathrm{~dB}$, radiation efficiency $-0.9512 \mathrm{~dB}(80.33$ $\%)$, total efficiency $-0.9522 \mathrm{~dB}(80.31 \%)$. As the difference between these two efficiency value is only $0.0011 \mathrm{~dB}$, the loss of impedance mismatch is low.

Table.1 Geometrical parameter of the proposed SIW cavity backed lateral and meander slots antenna

\begin{tabular}{|c|c|c|c|}
\hline Parametre & $\begin{array}{c}\text { Value } \\
(\mathbf{m m})\end{array}$ & Parametre & Value \\
\hline $\mathrm{L}$ & 14 & $\mathrm{~L}_{\mathrm{P} 1}$ & 13 \\
\hline $\mathrm{W}$ & 9 & $\mathrm{~W}_{\mathrm{P} 1}$ & 7.5 \\
\hline $\mathrm{P}$ & 1 & $\mathrm{~L}_{\mathrm{P} 2}$ & 12.5 \\
\hline $\mathrm{D}$ & 0.3 & $\mathrm{~W}_{\mathrm{P} 2}$ & 2.3 \\
\hline $\mathrm{L}_{\mathrm{ML}}$ & 8 & $\mathrm{t}_{\mathbf{P}}$ & 0.4 \\
\hline $\mathrm{L}_{\mathrm{MS}}$ & 4 & $\mathrm{~L}_{\mathrm{SL}}$ & 1.4 \\
\hline $\mathrm{W}_{\mathrm{M} 1}$ & 1 & $\mathrm{~L}_{\mathrm{SS}}$ & 0.7 \\
\hline $\mathrm{W}_{\mathrm{M} 2}$ & 0.5 & $\mathrm{~W}_{\mathrm{S}}$ & 0.8 \\
\hline SeL & 4 & $\mathrm{t}_{\mathrm{s}}$ & 0.1 \\
\hline
\end{tabular}

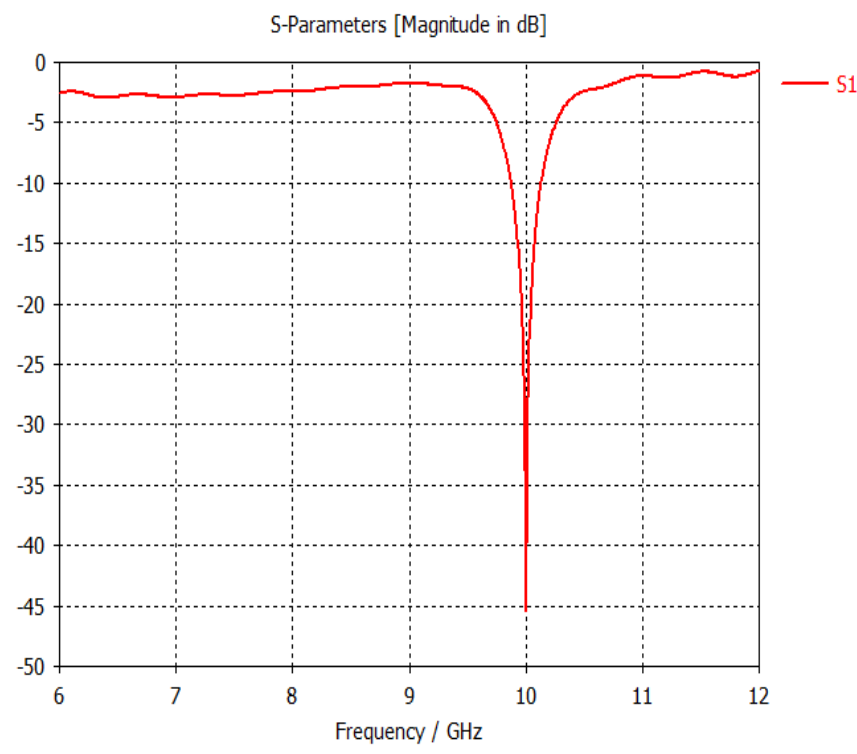

Fig 9: Simulation $S_{11}$-parameter of cavity back lateral and meander slots (proposed model) SIW antenna

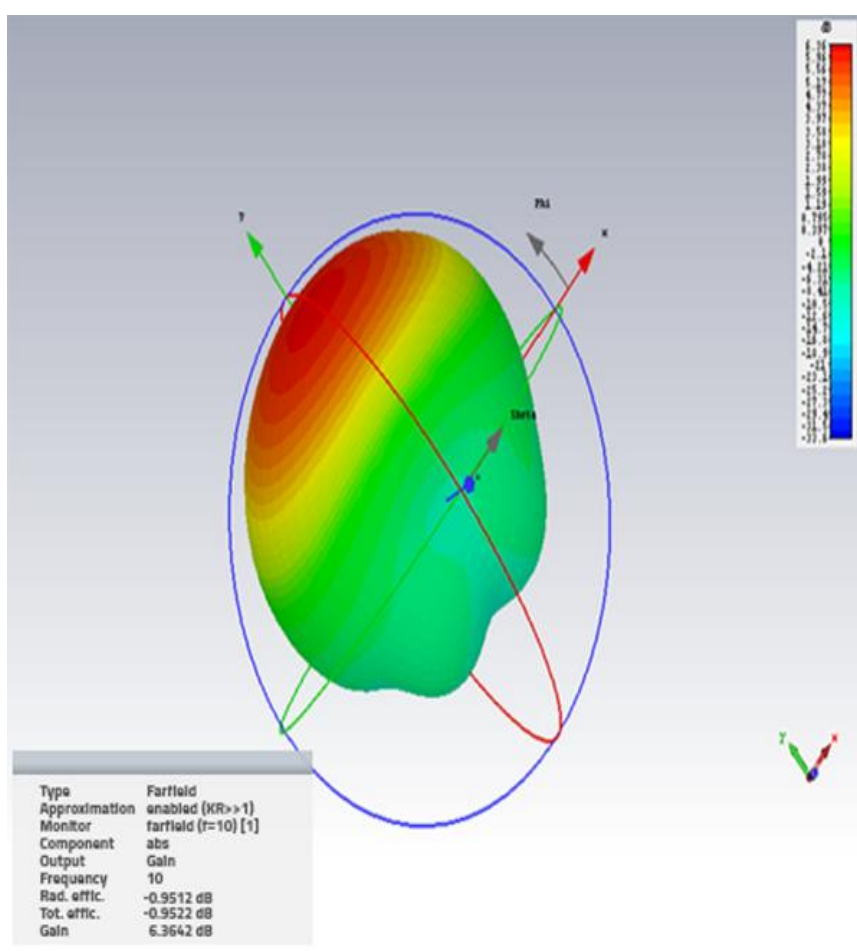

Fig 10.: Farfield 3D-plot gain of SIW cavity-backed antenna at $10 \mathrm{GHz}$

\subsection{Electric Field (E-field) and Magnetic Field (H-field) Distributions}

The polar plot radiation pattern of E-field and $\mathrm{H}$-field at resonating frequency $10 \mathrm{GHz}$ in three plane $\mathrm{XOY}, \mathrm{YOZ}$, and $\mathrm{XOZ}$ are shown in Figure 11 and 12.

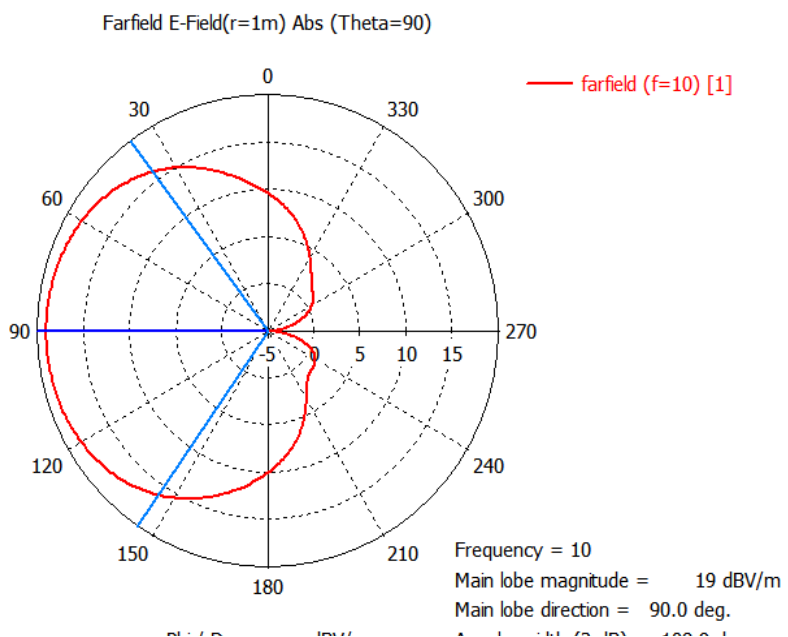

(a) 
Farfield E-Field $(r=1 \mathrm{~m})$ Abs (Phi $=90)$

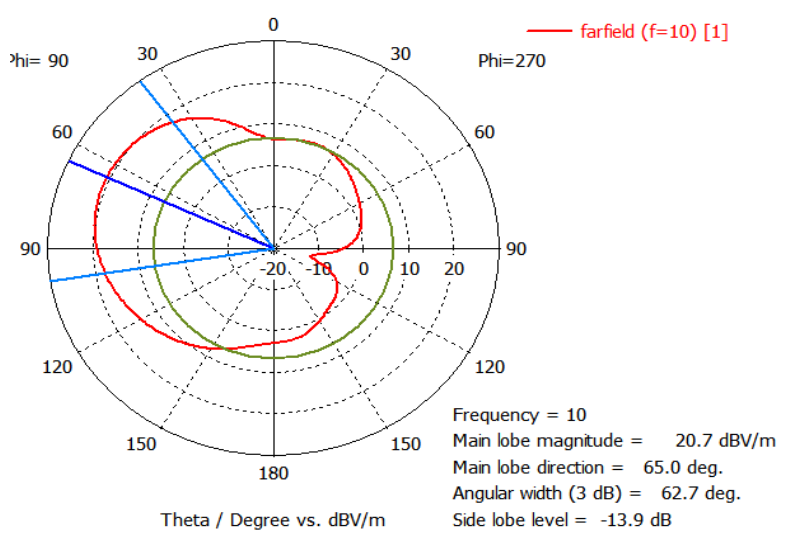

(b)

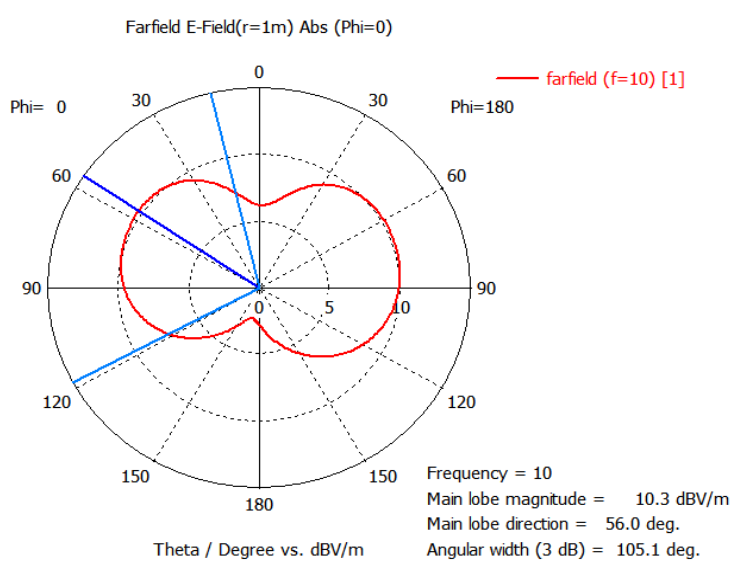

(c)

Fig 11 : Simulation polar plot of the radiation pattern in E-plane and at $10 \mathrm{GHz}$ (a) XOY plane (b) YOZ plane (C) XOZ plane

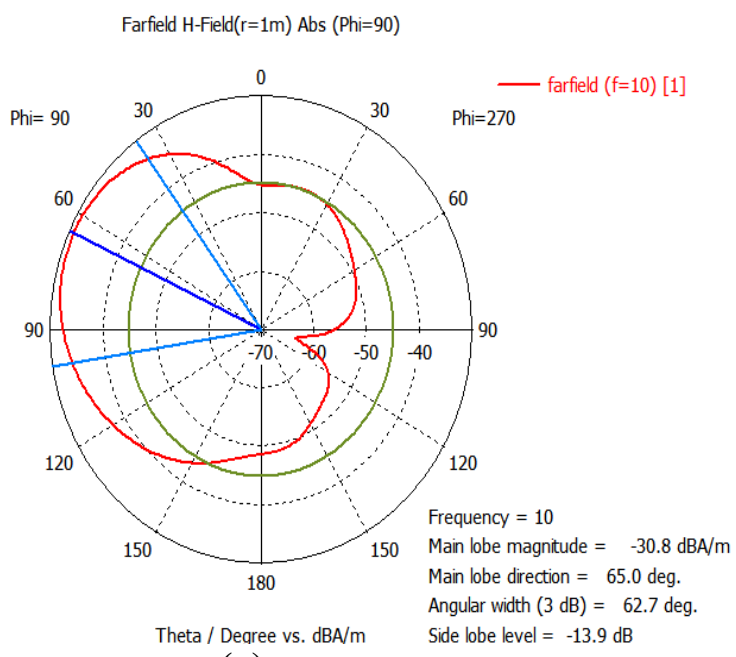

(a)

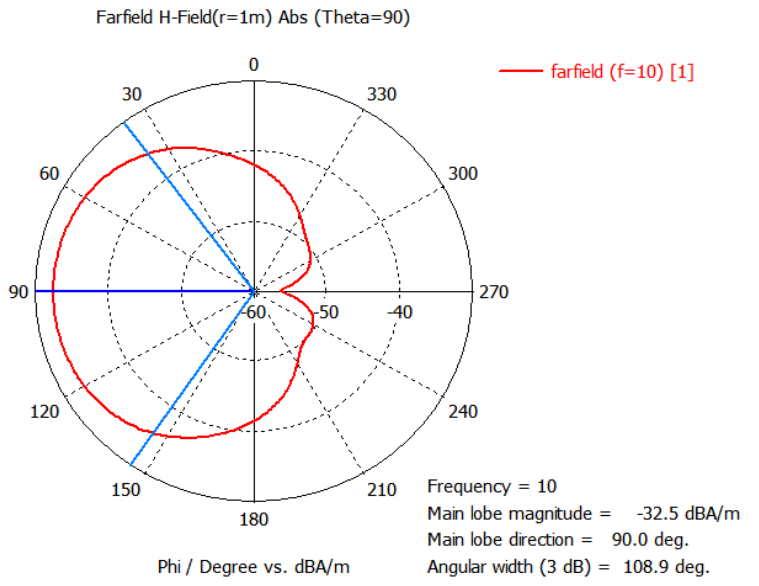

(b)

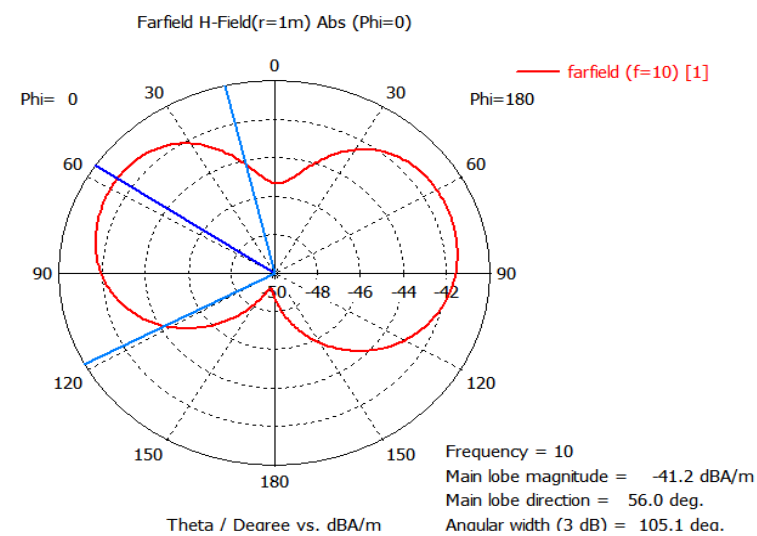

(C)

Fig 12: Simulation polar plot of the radiation pattern in $\mathrm{H}$ plane at $10 \mathrm{GHz}$ (a) XOY plane (b) YOZ plane (C) XOZ plane

The surface current distribution of proposed SIW cavitybacked antenna plot at $10 \mathrm{GHz}$ has been simulated as shown in Figure 13. the surface current distribution has a high value along the meander and lateral slots. The proposed antenna rejects the frequency that is located outside of the bandwidth ,so the surface current has no longer spread all over the cavity.
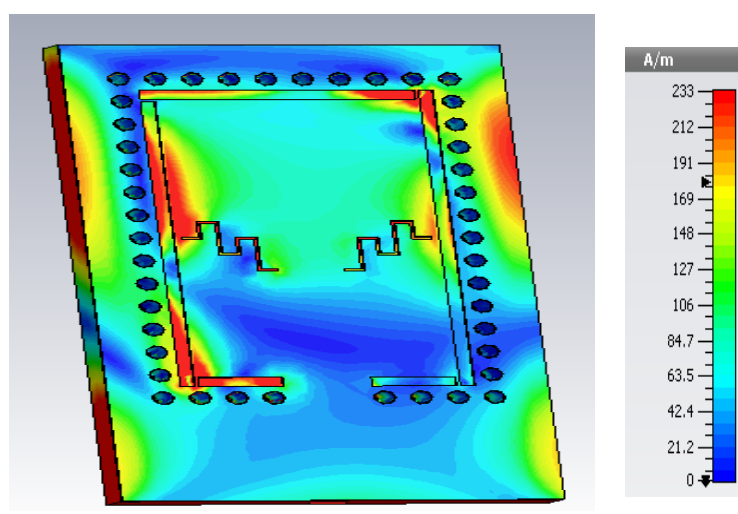

Fig 13:Surface current distribution at $10 \mathrm{GHz}$ 


\section{ANTENNA IMPLEMENTATION AND COMPARISON BETWEEN THE MEASUREMENT AND SIMULATION RESULTS}

Based on the analysis and simulations shown in this work, an experimental lateral and meander-shaped slot cavity backed SIW antenna has been fabricated. Figure 14 shows the photograph of the fabricated prototype of proposed antenna

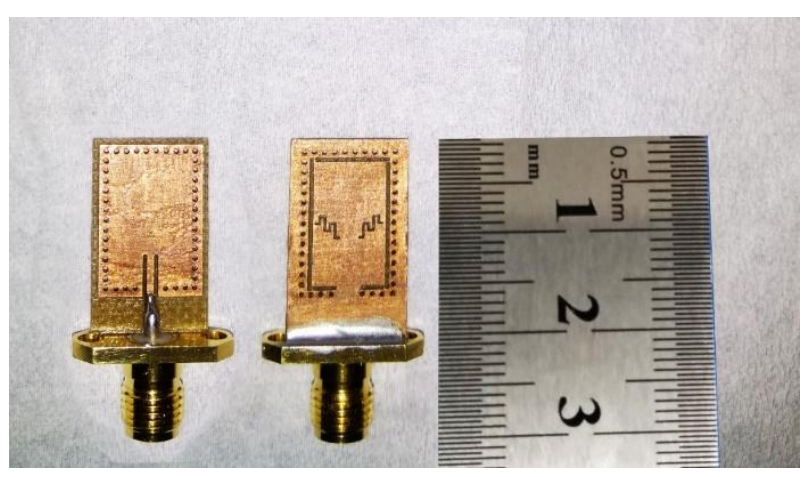

Fig 14: Photograph of the fabricated prototype of the lateral and meander-shaped slot cavity backed SIW antenna front and back view.

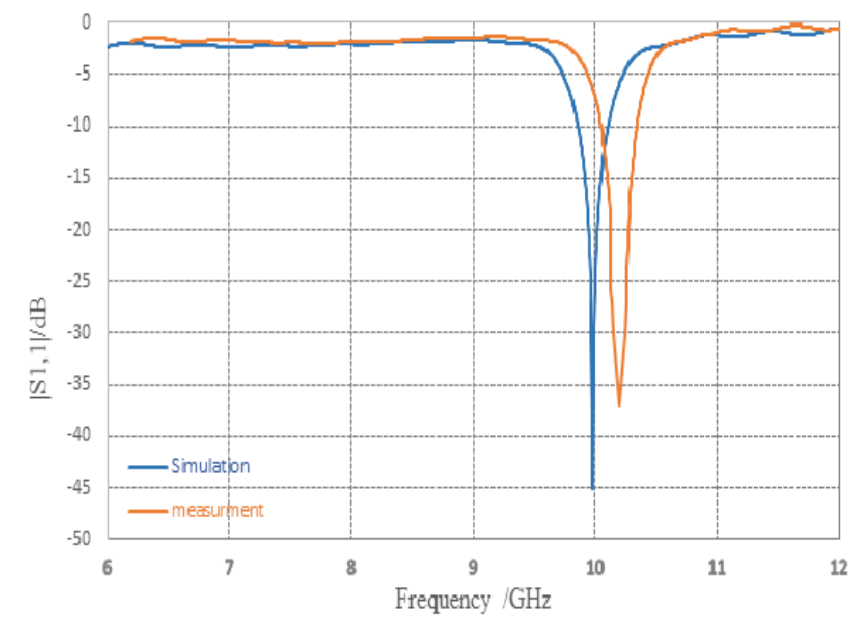

Fig 15: Comparison between the simulation(solid) and the measured (dashed) $S_{11}$-parameter for fabrication backed SIW cavity antenna.

The measured results reach an agreement with the electromagnetic (EM) simulation results in terms of $\mathrm{S}_{11^{-}}$ parameter as illustrated fig. 15, gain, and efficiency. However, measured return loss at $10.2 \mathrm{GHz}$ is about $-37.23 \mathrm{~dB}$ which somewhat higher than the simulation. This is because connector losses and unexpected material losses that could not be accounted in this simulations. this fractional bandwidth of about $3.38 \%$ centered at $10.2 \mathrm{GHz}$. Good out of gain is probably due to the unspecified values of $\varepsilon_{r}$ and possible fabrication errors. Table 2 summarizes simulation results of designed SIW antenna and experimental results of implemented proposed SIW antenna, this table shows the improvement of the performances first with un slotted cavitybacked antenna, then second adding the meander slots, and finally including the lateral slots. Good agreement between simulations and measurements results was obtained.
Table 2. summarizes simulation and experimental results

\begin{tabular}{|c|c|c|c|}
\hline Property & $\begin{array}{c}f_{\mathbf{O}} \\
\mathbf{G H z}\end{array}$ & $\begin{array}{c}\text { Return } \\
\text { Loss } \\
(\mathbf{d B})\end{array}$ & BW \% \\
\hline $\begin{array}{c}\text { Un slotted } \\
\text { lateral slots }\end{array}$ & 12.2 & -19 & 2.12 \\
\hline $\begin{array}{c}\text { Lateral and meander } \\
\text { slots }\end{array}$ & 10 & -45 & 2.65 \\
\hline Measured & 10.2 & -37.23 & 3.45 \\
\hline
\end{tabular}

\section{CONCLUSION}

A new design method of low profile cavity backed planar slot antenna is presented in this paper. The whole antenna including backed cavity and feeding element is completely constructed at a single substrate by using SIW technique and GCPW structure. Experiment was carried out to validate this design concept. The fabricated antenna has $2.65 \%$ bandwidth and keeps high radiation performance of conventional cavity backed antenna such as high gain, and low cross polarization level. It still has advantages of conventional planar antennas such as low profile, light weight, good conformability and seamless integration with planar circuit. It can be easily fabricated by ordinary single layer PCB process with very low cost.

\section{REFERENCES}

[1] G. Q. Luo, Z. F. Hu, L. X. Dong, and L. L. Sun, "Planar slot antenna backed by substrate integrated waveguide cavity," IEEE Antennas Wireless Propag. Lett., vol. 7, pp. 236-239, 2008.

[2] D. M. Pozar, "A microstrip antenna aperture coupled to a microstrip line,” Electron. Letters, vol. 21, pp. 49-50, Jan. 1985.

[3] R. Azadegan and K. Sarabandi, "A novel approach for miniaturization of slot antennas," IEEE Trans. Antennas Propag., vol. 51, no. 3, pp. 421-429, Mar. 2003.

[4] W. Hong, N. Behdad, and K. Sarabandi, "Size reduction of cavitybacked slot antennas," IEEE Trans. Antennas Propag., vol. 54, no. 5, pp. 1461-1466, May 2006.

[5] F. $\mathrm{Xu}$ and $\mathrm{K}$. Wu, "Guided-wave and leakage characteristics of substrate integrated waveguide," IEEE Trans. Microw. Theory Tech., vol. 53, no. 1, pp. 66-73, Jan. 2005.

[6] L. Yan, W. Hong, G. Hua, J. Chen, K. Wu, and T. Cui, "Simulation and experiment on SIW slot array antennas," IEEE Microw. Wireless Compon. Lett., vol. 14, no. 9, pp. 446-448, Sep. 2004.

[7] Wu K. 2003] K. Wu, D. Deslandes, and Y. Cassivi, "The substrate integrated circuits-anew concept for highfrequency electronics and optoelectronics," TELSKIS2003, Nis, Serbia and Montenegro, October 2003. 
[8] D. Deslandes, L. Perregrini, P. Arcioni, M. Bressan, K. $\mathrm{Wu}$, and $\mathrm{G}$. Conciauro, "Dispersion characteristics of substrate integrated rectangular waveguide," IEEE Microwave Wireless Compon. Lett., vol. 12, pp.333335, Sept. 2002.

[9] C. Calabrese and G. Marroco, "Meandered-slot antennas for sensor-RFID tags," IEEE Antennas Wireless Propag. Lett., vol. 7, pp. 5-8,2008.

[10] Luo, G.Q., Hu, Z.F., Dong, L.X., and L.L. Sun, "Planar slot antenna backed by substrate integrated waveguide cavity", IEEE Antennas Wirel. Propag. Lett., 2008, 7, pp. 236-239.
[11] Luo, G.Q., and L.L. Sun, "A reconfigurable cavity backed antenna for circular polarization diversity", Microw. Opt. Technol. Lett., 2009, 51, (6), pp. 14911493

[12] Hiroshi, U., Takeshi, T., and M. Fujii, "Development of a laminated waveguide", IEEE Trans. Microw. Theory Techn., 1998, 46, (12), pp. 2438-2443.

[13] S. Mukherjee, A. Biswas, and K. V. Srivastava," Bandwidth enhancement of Substrate Integrated Waveguide Cavity backed slot antenna by offset feeding technique", IEEE Applied Electromagnetics. Conf. (AEMC), 2013, pp- 1-2. 